\title{
GERMINAÇÃO IN VITRO DE MURICI-PEQUENO (Byrsonima intermedia A. Juss.)
}

\author{
In vitro germination of (Byrsonima intermedia A. Juss.)
}

\author{
Raírys Cravo Nogueira ${ }^{1}$, Renato Paiva ${ }^{2}$, Ana Hortência de Castro ${ }^{3}$, \\ Carlos Vinício Vieira ${ }^{4}$, Letícia Caravita Abbade ${ }^{4}$, Amauri Alves Alvarenga ${ }^{2}$
}

\section{RESUMO}

O murici-pequeno (Byrsonima intermedia A. Juss.), espécie medicinal do Cerrado, apresenta dificuldade de propagação sexuada decorrente da baixa taxa de germinação e emergência lenta das plântulas em campo. Objetivou-se com o presente trabalho estudar aspectos da germinação in vitro de murici-pequeno mediante avaliação do efeito dos meios de cultura MS e WPM e diferentes concentrações de BAP. Frutos maduros foram coletados de populações naturais, dos quais sementes e embriões foram excisados e utilizados como explante. Pelos resultados, infere-se que os meios de cultura mais eficientes para a germinação in vitro de sementes e embriões são o MS e WPM 50\%, sem sacarose, apresentando 60\% e $100 \%$ de germinação, respectivamente. Observou-se também que não se faz necessária a adição de BAP na germinação in vitro de embriões.

Termos para indexação: Germinação in vitro, murici-pequeno, plantas medicinais, Byrsonima intermedia.

\begin{abstract}
The murici-pequeno (Byrsonima intermedia A. Juss.) is a medicinal plant of cerrado that presents difficulties of sexual propagation due to a low rate of seed germination and plant emergency in the field. The objective of this work was study aspects of the in vitro germination of murici-pequeno evaluating the effects of MS and WPM culture media and different concentrations of BAP. Mature fruits were collected from native plants and their seeds and embryos excised and used as explants. The results indicated that the most effective culture media used for the in vitro seed and embryo germination vere MS and WPM 50\%, both with no sucrose, presenting 60 and 100\% germination, respectively. The use of BAP is not required for in vitro embryo germination.
\end{abstract}

Index terms: Germination in vitro, murici-pequeno, medicinal plant, Byrsonima intermedia.

(Recebido para publicação em 23 de outubro de 2003 e aprovado em 13 de agosto de 2004)

\section{INTRODUÇÃO}

São poucos os estudos sobre a germinação de espécies nativas do Cerrado. Com o crescente interesse por parte dos pesquisadores, aos poucos se revela o potencial dessa vegetação (COELHO, 1999).

No caso do murici-pequeno (Byrsonima intermedia A. Juss.), um arbusto medicinal cujo chá da casca do caule apresenta atividade adstringente nas diarréias e disenterias, não foram encontrados relatos na literatura quanto ao seu processo de germinação. Há, no entanto, em Lorenzi (2002), menção sobre a ocorrência de baixa taxa de germinação e emergência lenta em outras espécies de Byrsonima, como B. coccolobifolia, B. lancifolia, B. sericea, B. spicata, B. stipulacea e B. verbacifolia.

Para que o processo de germinação ocorra, é necessário que as sementes estejam viáveis, que as condi- ções ambientais sejam favoráveis e que as sementes não estejam dormentes (BEWLEY e BLACK, 1984).

Durante o cultivo in vitro, as soluções de sais e açúcares que compõem os meio de cultura não exercem efeito puramente nutritivo, mas também influenciam o crescimento celular e a morfogênese por meio de propriedades osmóticas (GEORGE, 1996).

Diversas formulações de meios básicos têm sido utilizadas no cultivo in vitro. Não há uma formulação-padrão, mas o meio MS (MURASHIGE e SKOOG, 1962), com suas modificações e diluições, tem sido utilizado com sucesso para diversas espécies. Com espécies lenhosas, entretanto, o meio MS não se mostra satisfatório em alguns casos e composições mais diluídas em macronutrientes apresentam melhor desempenho (GRATTAPAGLIA e MACHADO, 1998). O meio nutritivo WPM (LLOYD e MCCOWN, 1981), por exemplo, apre-

1. Doutoranda em Agronomia/Fisiologia Vegetal - Universidade Federal de Lavras/UFLA - Caixa Postal 3037 - $37200-000$ - Lavras, MG.

2. Professores do Departamento de Biologia/UFLA

3. Doutora em Agronomia/Fisiologia Vegetal/UFLA

4. Estudantes de iniciação científica CNPq/UFLA. 
senta $25 \%$ das concentrações de íons nitrato e amônia do meio MS, além de mais potássio e um alto nível de íons sulfato, tendo sido amplamente utilizado para a micropropagação de espécies lenhosas (PASQUAL, 2001).

Segundo Souza (2003), dependendo da espécie, não há necessidade de suplementação do meio com sacarose. Porém, pode ser que ao se adicionar sacarose ao meio de cultura, consiga-se manter a plântula in vitro por um período de tempo maior.

Objetivou-se com o presente trabalho estudar aspectos da germinação in vitro de murici-pequeno.

\section{MATERIAL E MÉTODOS}

\section{Procedência do material vegetal}

Frutos maduros e inflorescências de muricipequeno foram coletados de populações naturais localizadas no município de Ijaci, região sul do Estado de Minas Gerais, localizado a 918,0 m de altitude, $21^{\circ} 14^{\prime} \mathrm{S}$ de latitude e longitude $44,9^{\circ} 00^{\prime} \mathrm{W}$ GRW.

Após a coleta, os frutos passaram por processo de beneficiamento, com retirada da polpa, imersão em hidróxido de sódio $(\mathrm{NaOH})$ 0,1 M por 5 minutos e lavagem em água corrente com auxílio de peneira por 10 minutos. Após a secagem, os frutos foram armazenados em sacos de papel a $10^{\circ} \mathrm{C}$.

As inflorescências foram utilizadas para a confirmação da espécie e preparo de exsicata, que se encontra depositada no herbário ESAL do Departamento de Biologia da Universidade Federal de Lavras (UFLA), sob registro $\mathrm{n}^{\mathrm{o}} 17.601$.

Os experimentos de germinação foram conduzidos no Laboratório de Cultura de Tecidos de Plantas da Universidade Federal de Lavras, Setor de Fisiologia Vegetal, Lavras - MG, 2003.

\section{Efeito de diferentes meios de cultura, pre- sença de sacarose e tipo de explante na germinação de murici-pequeno}

A abertura dos endocarpos foi realizada manualmente com o auxílio de martelo. Após a retirada das sementes, essas foram imersas em álcool $70 \%(\mathrm{v} / \mathrm{v})$ por 30 segundos e, em seguida, em solução de $\mathrm{NaOCl} 0,5 \%$ de cloro ativo por 5 minutos. Em câmara de fluxo laminar, as sementes foram lavadas em água destilada autoclavada (a $120^{\circ} \mathrm{C}$, durante 20 minutos) e tiveram seus tegumentos retirados, de acordo com a necessidade do experimento. Posteriormente, sementes intactas e sem tegumento (embriões) foram novamente imersas em solução de $\mathrm{NaOCl} 0,5 \%$ de cloro ativo por 5 minutos e, ao final desse tempo, lavadas por quatro vezes em água destilada e autoclavada e, em seguida, inoculadas em tubos de ensaio contendo os tratamentos.

Foram testados os meios de cultura WPM $100 \%$ e $50 \%$, MS $100 \%$ e $50 \%$, acrescidos ou não de $3 \%$ de sacarose. Em cada um foram utilizados diferentes tipos de explantes: embrião ou sementes. Os meios foram solidificados com ágar $0,7 \%$ e o $\mathrm{pH}$ foi aferido para 5,8 antes da autoclavagem a $120^{\circ} \mathrm{C}$, durante 20 minutos. Após a inoculação, os explantes foram mantidos em sala de crescimento sob irradiância de $43 \mu \mathrm{mol} \mathrm{m} \mathrm{m}^{-2} \mathrm{~s}^{-1}$, fotoperíodo de 16 horas e temperatura de $27 \pm 2{ }^{\circ} \mathrm{C}$. A avaliação foi realizada após 30 dias de incubação, sendo observado o porcentual de germinação.

O experimento foi constituído de três repetições, sendo cada uma composta por cinco tubos de ensaio e cada tubo contendo um explante.

A detecção de diferenças significativas foi feita por meio da análise de "Deviance". Para o ajuste do modelo, considerou-se a transformação denominada como logito para a estimativa da proporção de germinação de sementes e embriões (DEMÉTRIO, 1993):

$$
\log i t o\left(\mu_{i}\right)=\ln \left(\frac{\mu_{i}}{1-\mu_{i}}\right)=\mu+\delta_{i}+\alpha_{j}
$$

em que $\mu$ representa a média geral ; $\delta_{\mathrm{i}}$, o efeito de sacarose $(\mathrm{i}=0,1)$ e $\alpha_{\mathrm{j}}$, efeito do meio de cultura $(\mathrm{j}=1,2,3,4)$.

\section{Efeito da citocinina BAP na germinação in vitro de murici-pequeno}

O processo de assepsia das sementes foi semelhante ao realizado no experimento anterior. Em câmara de fluxo laminar, efetuou-se a retirada dos tegumentos das sementes.

Foram testados quatro níveis de $\operatorname{BAP}(0,0 ; 0,5$; 1,0 e $2,0 \mathrm{mg} \mathrm{L}^{-1}$ ) acrescido ao meio de cultura WPM $50 \%$ com $3 \%$ de sacarose. Os meios foram solidificados com ágar $0,7 \%$ e o $\mathrm{pH}$, aferido para 5,8 antes da autoclavagem a $120^{\circ} \mathrm{C}$, durante 20 minutos. Após a inoculação, os embriões foram mantidos em sala de crescimento sob irradiância de $43 \mu \mathrm{mol} \mathrm{m} \mathrm{s}^{-2}$, fotoperíodo de 16 horas e temperatura de $27 \pm 2^{\circ} \mathrm{C}$. A avaliação foi realizada após 45 dias de incubação, sendo observado o porcentual de germinação.

O experimento foi constituído de cinco repetições, sendo cada uma composta por cinco tubos de ensaio e cada tubo contendo um explante. 
Para cada parcela, realizou-se a contagem de unidades germinadas. A proporção foi obtida em relação ao número total de tubos de ensaio por parcela, isto é, $\mathrm{n}=25$. A deteç̧ão de diferenças significativas foi feita por meio da análise de "Deviance".

\section{RESULTADOS E DISCUSSÃO}

Efeito de diferentes meios de cultura, presença de sacarose e tipo de explante na germinação de murici-pequeno

No cultivo de embriões, a máxima porcentagem de germinação $(100 \%)$ foi obtida quando cultivados em meio WPM 50\%, na ausência de sacarose. No cultivo de sementes, a maior porcentagem de germinação também foi obtida em WPM $50 \%$, na ausência de sacarose, ocorrendo aproximadamente $60 \%$ de germinação (Figura 1).

Para a indicação do meio de cultura mais apropriado para a germinação de embriões e sementes de murici-pequeno, procedeu-se ao ajuste de um modelo generalizado, segundo Demétrio (1993) (Tabela 1).
Os efeitos da sacarose e do meio de cultura foram significativos para a análise de germinação de embriões. Observou-se que o acréscimo de sacarose nos meios testados alterou as porcentagens de germinação. Nos meios WPM, WPM 50\% e MS, houve menor porcentagens de germinação, ao passo que no MS 50\% houve maior germinação. Entretanto, a presença de sacarose no meio WPM 50\%, apesar de ter ocasionado uma diminuição na porcentagem de germinação em comparação com o meio em que não se acresceu a sacarose, ainda ocorreu em valor elevado (95\%).

Nos meios WPM e MS, a presença de sacarose ocasionou uma considerável redução na germinação. Provavelmente, a concentração completa dos sais, juntamente com a sacarose, afetou o balanço osmótico, prejudicando o processo germinativo. Entretanto, esses mesmos meios, quando utilizados com metade das concentrações de sais e na presença de sacarose, não apresentaram mudanças consideráveis na taxa de germinação, chegando essa até a aumentar no meio MS 50\%. A redução da concentração dos sais parece ter compensado a adição de sacarose, não afetando, assim, o balanço osmótico e sendo favorável à germinação.

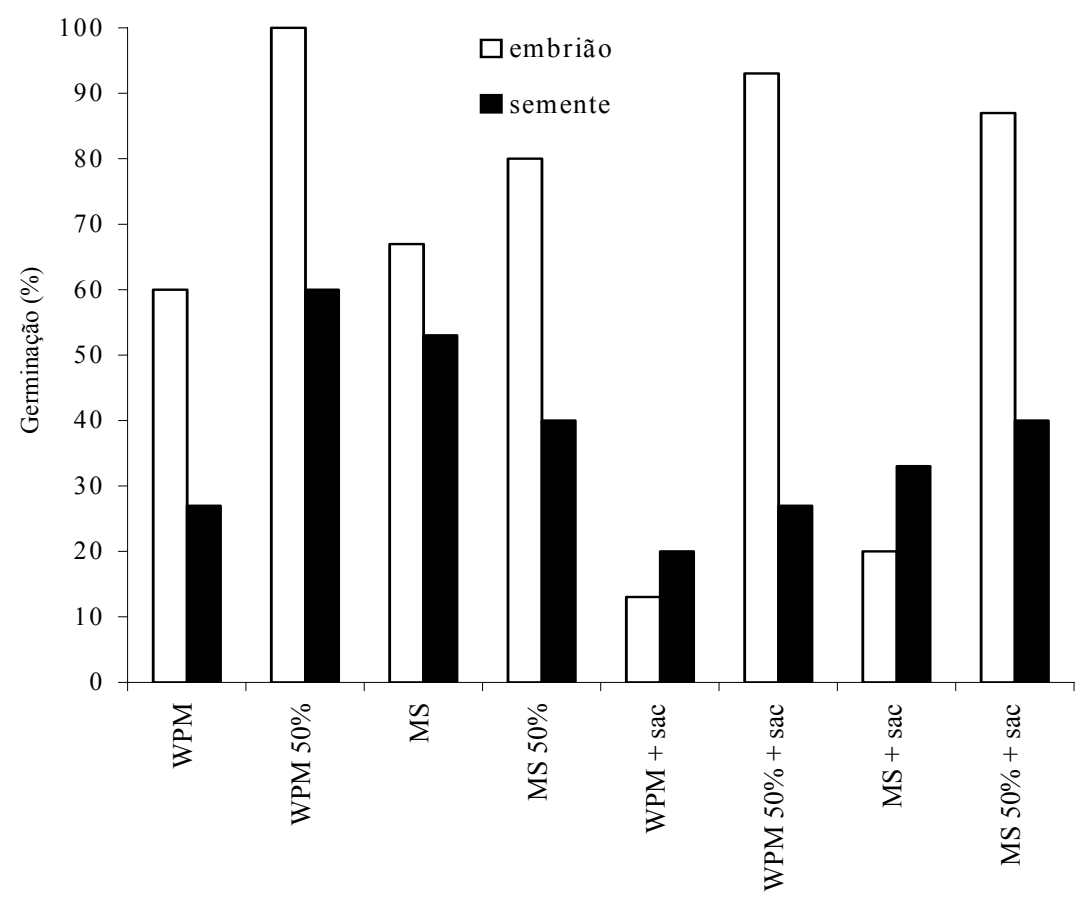

FIGURA 1 - Germinação de embriões e sementes de murici-pequeno em diferentes meios de cultura (MS ou WPM), na presença ou ausência de sacarose. 
Os resultados obtidos com embriões foram semelhantes aos encontrados por Souza (2003) que, testando diferentes concentrações do meio MS (completo, $50 \%$ e $25 \%$ ) líquido ou sólido na germinação de embriões de arnica (Lychnophora pinaster), observou que o MS $25 \%$ sólido foi o meio que proprocionou melhor resultado, aproximadamente $68 \%$ de germinação. O MS em sua concentração original apresentou porcentagem de germinação inferior a 50\%. A autora também comparou os meios MS 25\%, WPM e WPM 50\%, todos sólidos, na presença e ausência de sacarose. Os meios MS 25\% sem sacarose, MS 25\% com sacarose e WPM 50\% sem sacarose não diferiram entre si e diferiram dos demais meios de cultura, apresentando as maiores porcentagens de germinação, respectivamente, $79 \%, 70 \%$ e $70 \%$.
Já para o cultivo de sementes, a adição de sacarose nos meios de cultura promoveu uma redução nãosignificativa na porcentagem de germinação. No meio MS 50\%, por exemplo, a porcentagem de germinação praticamente não sofreu alteração, em comparação ao mesmo meio acrescido de sacarose.

Pelos resultados apresentados na Tabela 2, verifica-se, por meio do teste de Razão de Chances, que o meio WPM 50\%, preferencialmente na ausência de sacarose, é mais apropriado para germinação de embriões.

Pelos resultados apresentados na Tabela 3, constata-se, por meio da razão de chances, que os meios WPM 50\% e MS são os mais apropriados para germinação de sementes, independente da presença ou ausência de sacarose.

TABELA 1 - Análise da "Deviance" dos efeitos sacarose (sac) e meio nutritivo para a germinação de embriões e sementes de murici-pequeno.

\begin{tabular}{cccc}
\hline \multicolumn{4}{c}{ Variável: Proporção de Embriões Germinados } \\
\hline FV & GL & Valor Qui-Quadrado & p-valor \\
\hline SAC & 1 & 9.1027 & 0.0026 \\
MEIO & 3 & 44.4466 & 0.0001 \\
\hline \multicolumn{4}{c}{ Variável: Proporção de Sementes Germinadas } \\
\hline SAC & GL & Valor Qui-Quadrado & p-valor \\
MEIO & 1 & 2.938 & 0.0841 \\
\hline
\end{tabular}

TABELA 2 - Análise dos coeficientes e razão de chances para embriões de murici-pequeno inoculados em meio MS e WPM na ausência e presença de sacarose (sac).

\begin{tabular}{lccccc}
\hline \multicolumn{1}{c}{ Parâmetro } & GL & Estimativa & Erro padrão & p-valor & Razão de Chances \\
\hline Intercepto & 1 & 1,0319 & 0,5229 & 0,0485 & \\
Sac 0 & 1 & 1,5452 & 0,5057 & 0,0022 & 4,673 \\
Sac $3 \%$ & 0 & 0,0000 & 0,0000 & $\cdot$ & \\
WPM & 1 & $-2,4337$ & 0,6734 & 0,0003 & 0,087 \\
WPM 50\% & 1 & 1,8212 & 1,1433 & 0,1112 & 6,122 \\
MS & 1 & $-2,1145$ & 0,6611 & 0,0014 & 0,120 \\
MS 50\% & 0 & 0,0000 & 0,0000 &. & \\
\hline
\end{tabular}

Ciênc. agrotec., Lavras, v. 28, n. 5, p. 1053-1059, set.out., 2004 
Apesar de o meio MS ser mais concentrado que o meio WPM 50\%, este apresentou as mesmas chances de germinação. A diferença de concentrações de sais entre esses meios parece não ter afetado o processo germinativo das sementes. Efeitos não-significativos do meio nutritivo para a germinação de sementes também foram observados por Conceição (2000), que testou diferentes concentrações do meio MS na germinação de sementes de timbó (Derris urucu).

A maior germinação de embriões em meio nutritivo WPM 50\% deve-se, provavelmente, à diminuição do potencial osmótico promovido pela redução das concentrações de macro e micronutrientes do referido meio, que é menos concentrado, em comparação aos outros meios utilizados.

O mesmo pode ser concluído para as maiores chances de germinação de embriões, as quais foram observadas na ausência de sacarose. A presença de sais e de carboidratos possivelmente interferiu na regulação osmótica do meio de cultura e, conseqüentemente, na disponibilidade de água para o processo de embebição na germinação. A ausência de sacarose no meio WPM $50 \%$ disponibilizou mais água para o explante, desencadeando o processo de protusão da radícula, devido à retomada do crescimento do embrião acionada pela embebição.

Os valores observados na germinação de sementes de murici-pequeno podem estar associados ao tegumento, o qual parece retardar o processo germinativo, ocasionando a baixa porcentagem de germinação. Esse pode ter servido como uma barreira para a entrada de água, inibindo, assim, a ativação de enzimas responsáveis pela germinação.

Azevedo (2003) obteve maiores porcentagens de germinação in vitro em sementes de copaíba (Copaiba langsdorffii) em meio de cultura MS na ausência de sacarose. Resultados semelhantes também foram obtidos em sementes de Annona glabra (DECCETTI, 2000).

Sementes de moreira (Maclura tinctoria), no entanto, germinaram em maior porcentagem quando cultivadas em meios com sacarose, porém, em menores concentrações (GOMES, 1999).

\section{Efeito da citocinina BAP na germinação de embriões de murici-pequeno}

Não foi possível a aplicação de uma análise estatística satisfatória em virtude da ocorrência de calos em todos os tratamentos utilizados, uma vez que objetivouse neste experimento estimular a germinação e induzir múltiplas brotações em embriões zigóticos por meio da aplicação de BAP.

As plântulas malformadas foram consideradas as que apresentaram formação de calos e ausência de raiz. As plântulas consideradas normais foram aquelas que apresentaram comprimento próximo a $1,0 \mathrm{~cm}$ e ausência de calos (Figura 2).

TABELA 3 - Análise dos coeficientes e razão de chances para a proporção de sementes de murici-pequeno inoculados em meio MS e WPM na ausência e presença de sacarose (sac).

\begin{tabular}{lccccc}
\hline \multicolumn{1}{c}{ Parâmetro } & GL & Estimativa & Erro Padrão & p-valor & Razão de Chances \\
\hline Intercepto & 1 & $-0,7501$ & 0,4311 & 0,0819 & \\
Sac 0 & 1 & 0,6668 & 0,3894 & 0,0868 & 1,95 \\
Sac 3\% & 0 & 0,0000 & 0,0000 & $\cdot$ & \\
WPM & 1 & $-0,8026$ & 0,5771 & 0,1643 & 0,448 \\
WPM 50\% & 1 & 0,1409 & 0,5311 & 0,7908 & 11,513 \\
MS & 1 & 0,1409 & 0,5311 & 0,7908 & 11,513 \\
MS 50\% & 0 & 0,0000 & 0,0000 & & \\
\hline
\end{tabular}


Provavelmente, as folhas cotiledonares, ao entrarem em contato com o meio de cultura, foram estimuladas a multiplicar suas células de maneira desorganizada, de forma que o desenvolvimento normal da plântula foi comprometido (Figura 3).

Embora as citocininas sejam indicadas para reduzir a dominância apical, a sua presença no meio de cultura deve ter favorecido a divisão celular, induzindo uma proliferação desorganizada. O BAP parece ter favorecido o balanço hormonal para a formação de calos, em vez de múltiplas brotações, que era o resultado esperado.

Resultados desfavoráveis também foram obtidos na cultura de embriões de coqueiro-anão (Cocos nucifera), com a utilização de diferentes concentrações de BAP ou a interação BAP x AIA. A inclusão de reguladores no meio de cultura ocasionou o início da germinação, mas com posterior escurecimento e morte dos embriões (SILVA, 2002).

Em pesquisa com guarirobeira (Syagros oleraceae), testaram-se diferentes níveis do meio MS em combinação com diferentes concentrações de BAP, tendo sido observada uma redução gradativa no número de folhas e peso médio da matéria seca da plântula, à medida que a concentração de BAP foi aumentada (MELLO, 2000).

Embora a citocinina atue na quebra do efeito do ácido abscísico (ABA), inibidor do processo germinativo, isso não foi observado nos experimentos, uma vez que a presença de BAP não potencializou a germinação.

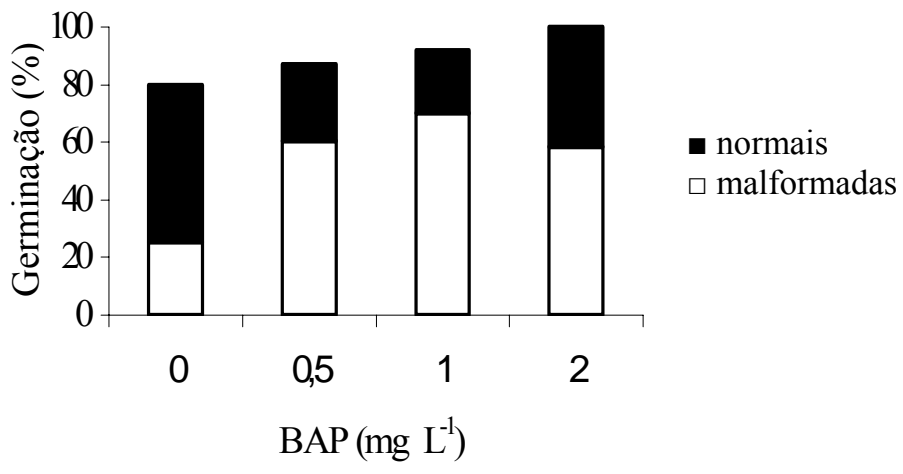

FIGURA 2 - Germinação de embriões de murici-pequeno cultivados em meio acrescido de diferentes concentrações de BAP.
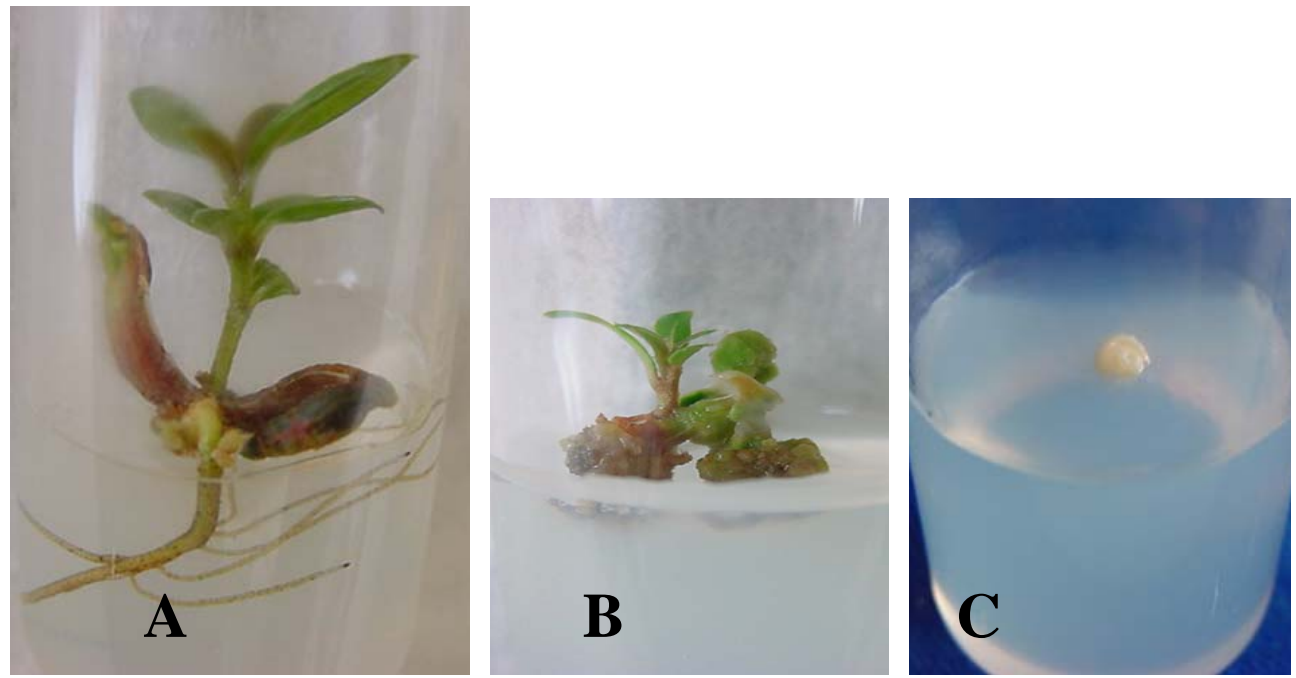

FIGURA 3 - Plântula normal (A) e plântula malformada (B) obtidas de embriões de murici-pequeno inoculados em diferentes concentrações de BAP (C).

Ciênc. agrotec., Lavras, v. 28, n. 5, p. 1053-1059, set.out., 2004 
Pelos resultados desses experimentos, demonstra-se que a adição dessa citocinina não é necessária para a germinação de murici-pequeno, uma vez que pode desencadear processos morfogênicos não-desejáveis, como a formação de calos, constituindo-se num obstáculo para a obtenção de fontes assépticas e com diferentes tipos de explantes para a micropropagação.

\section{CONCLUSÕES}

Os meios de cultura mais eficientes para a germinação de sementes e embriões são o MS e WPM $50 \%$, sem sacarose.

Não se faz necessária a adição de BAP para germinação in vitro de embriões de murici-pequeno.

\section{REFERÊNCIAS BIBLIOGRÁFICAS}

AZEVEDO, K. de S. Indução e análises bioquímicas de calos e aspectos da anatomia foliar de copaíba (Copaíba langsdorffii Desf.). 2003. 86 p. Dissertação (Mestrado em Fitotecnia) - Universidade Federal de Lavras, Lavras, 2003.

BEWLEY, J. D.; BLACK, M. Seeds: physiology of development and germination. 2. ed. New York: Plenum, 1984. 445 p.

COELHO, M. C. F. Germinação de sementes e propagação in vitro de sucupira branca [Pterodon pubescens (Benth)]. 1999. 119 p. Dissertação (Mestrado em Fitotecnia) - Universidade Federal de Lavras, Lavras, 1999.

CONCEIÇÃO, H. E. O. da. Cultivo in vitro, nutrição mineral e quantificação de rotenóides em timbós (Derris sp). 2000. 191 p. Tese (Doutorado em Fitotecnia) - Universidade Federal de Lavras, Lavras, 2000.

DECCETTI, S. F. C. Propagação in vitro de Annona glabra L. 2000. 101 p. Dissertação (Mestrado em Fisiologia Vegetal) - Universidade Federal de Lavras, Lavras, 2000.

DEMÉTRIO, C. G. B. Métodos lineares na experimentação agronômica. In: SIMPÓSIO DE ESTATÍSTICA APLICADA A EXPERIMENTAÇÃO AGRÔNOMICA, 5., 1993, Porto Alegre. Anais... Porto Alegre: [s.n.], 1993. p. 125.
GEORGE, E. F. Plant propagation by tissue culture: part 1: the technology. Edington: Exegetics, 1996. 574 p.

GOMES, G. A. C. Propagação in vitro de Moreira (Maclura tinctoria). 1999. 92 p. Dissertação (Mestrado em Fisiologia Vegetal) - Universidade Federal de Lavras, Lavras, 1999.

GRATTAPAGLIA, D.; MACHADO, M. A. Micropropagação. In: TORRES, A. C.; CALDAS, L. S.; BUSO, J. A. Cultura de tecidos e transformação genética de plantas. Brasília: EMBRAPA-SPI/EMBRAPA-CNPH, 1998. v. 1, p. 183-260.

LLOYD, G.; MCCOWN, B. Commercially-feasible micropropagation of Mountain laurel, Kalmia latifolia, by use of shoot tip culture. International Plant Propagation Society Proceedings, Washington, v. 30, p. 421-427, 1981.

LORENZI, H. Árvores brasileiras: manual de identificação e cultivo de plantas arbóreas nativas do Brasil. São Paulo: Nova Odessa, 2002. v. 1, 386 p.

MELLO, B. de. Cultivo de embriões in vitro da guarirobeira [Syagrus oleracea (Mart) Becc. ]. 2000. 117 p. Tese (Doutorado em Fitotecnia) - Universidade Federal de Lavras, Lavras, 2000.

MURASHIGE, T.; SKOOG, F. A revised medium for rapid growth and bioassays with tobacco tissue cultures. Physiologia Plantarum, Copenhagen, v. 15, n. 3, p. 473-497, Mar. 1962.

PASQUAL, M. Textos acadêmicos: meios de cultura. Lavras: FAEPE/UFLA, 2001. 127 p.

SILVA, V. dos S. Regeneração in vitro de embriões de Cocos nucifera. 2002. 78 f. Dissertação (Mestrado em Fisiologia e Bioquímica de Plantas) - Escola Superior de Agricultura Luiz de Queiroz, Piracicaba, 2002. Disponível em: <http://www.teses.usp.br/teses/disponiveis/11/11144/tde-22102002-154541/publico/vanda. pdf $>$. Acesso em: 03 jun. 2003.

SOUZA, A. V. de. Propagação in vitro e aspectos anatômicos de arnica [Lychnophora pinaster (Mart.)]. 2003. 126 p. Dissertação (mestrado em Fitotecnia) - Universidade Federal de Lavras, Lavras, 2003. 